\title{
Sistem Quality Control Gudang Menggunakan Sensor DT-I/O Infrared Receiver 991-121, Push Email dan Mikrokontroler Arduino Uno pada PT Multiprima Food
}

\author{
Wahyudi Purnama ${ }^{1}$, Viktory Hendrico ${ }^{2}$, Dede Ariyono ${ }^{3}$, Dolly Virgian Shaka Yudha Sakti ${ }^{4}$ \\ Teknik Informatika, Universitas Budi Luhur \\ Jl. Ciledug Raya, Petukangan Utara, Jakarta Selatan \\ wahyudipurnama17@gmail.com¹, viktoryhendrico@gmail.com², dedeassunnah@gmail.com ${ }^{3}$, \\ dolly.virgianshaka@budiluhur.ac.id ${ }^{4}$
}

\begin{abstract}
A good product is a product that assured its quality, to achieve high quality which fulfill the required standard and satisfy consumers can not be separated from the role of Quality Control. A food distribution business needs to improve the quality of food and also service to customers. In PT Multiprima Food food quality protection in the warehouse is well protected as SOP which have been made. But not a guarantee that food will be fully protected, food is known damaged or not frequently found when inclusion into the truck to be shipped. But it is frequently unreported or inaccurate due to not maximal way and implementation of reporting and company needs solution for effective implementation to office and head of warehouse which immediately remember the corrective action will usually be done by providing socialization or continuous training to all teams in improving the quality. In this research will be discussed about Quality Control system in the warehouse by using censor DT-I/O infrared receiver 991 - 121, push email and microcontroller arduino uno in PT. Multiprima Food which aim to provide solution to company and head of warehouse in reporting and action. This application produces good reporting in every step which be done. Either doing the input, shipment, completion, problem or action and also notification sound which can help head of warehouse to know the condition of whole process in the warehouse.
\end{abstract}

Intisari- Produk yang baik adalah produk yang berkualitas, untuk mencapai kualitas tinggi serta memenuhi standar dan memuaskan konsumen tidak lepas dari peranan Quality Control. Sebuah bisnis distributor makanan sangat memerlukan kualitas terhadap makanan tersebut dan juga pelayanan terhadap pelanggan, pada PT Multiprima Food penjagaan kualitas makanan pada gudang sangat terjaga sesuai SOP yang telah dibuat. Namun tidak menjadi jaminan bahwa makanan tersebut akan terjaga sepenuhnya, makanan tersebut diketahui rusak atau tidaknya lebih sering ditemukan pada saat pemasukan ke truk untuk dikirim. Tetapi seringkali tidak terlaporkan apalagi pemberian tindakan karena tidak maksimalnya cara penerapan pelaporan. Perusahaan memerlukan solusi untuk pelaporan yang efektif terhadap kantor dan kepala gudang langsung, mengingat tindakan perbaikan biasanya akan dilakukan dengan memberikan sosialisasi atau training secara berkesinambungan pada semua tim dalam meningkatkan kualitas. Pada penelitian ini akan dibahas mengenai sistem quality control gudang menggunakan sensor DT-I/O infrared receiver 991-121, push email dan mikrokontroler arduino uno pada PT MULTIPRIMA FOOD yang bertujuan dapat memberikan solusi kepada perusahaan dan kepala gudang dalam pelaporan dan tindakan. Aplikasi ini menghasilkan pelaporan dengan baik di setiap langkah yang dilakukan, baik melakukan pemasukan, pengeluaran, penyelesaian masalah ataupun tindakan dan juga suara notifikasi membantu kepala gudang mengetahui kondisi seluruh proses pada gudang.

Kata Kunci-Arduino Uno, Sensor DT-I/O Infrared Receiver 991-121, Quality Control, MySQL, Java.

\section{Pendahuluan}

Pada abad ke-21, teknologi yang berhubungan dengan sistem operasional bidang pengolahan dan distribusi informasi mengalami perkembangan pesat. Sebagai contoh yaitu sensor yang merupakan perangkat serba bisa dan hasilnya bisa dirasakan langsung.

Perkembangan komputer dan teknologi sensor untuk Quality control sampai saat ini semakin optima. Contohnya Finger Print, atau biasa disebut Sensor Pintu Otomatis. Peningkatkan quality control membutuhkan teknologi informasi untuk membantu mengolah jumlah data yang dibutuhkan sekaligus diproses oleh orang yang sama dan juga memerlukan sinkronisasi beberapa control (Leao et al., 2014). Perkembangan yang terjadi menimbulkan kecenderungan positif yang membuat kegiatan manusia jadi lebih mudah dan praktis.

Pada perusahaan yang bergerak dalam bidang penjualan makanan, Quality control merupakan sebuah jaminan yang dibutuhkan oleh para pelanggan. Jika pengecekan dan, pengiriman untuk menegtahui ada atau tidaknya kesrusakan dan tindakan penanganan kendala tidak terlaporkan dapat mengakibatkan kualitas pelayanan dan kualitas kinerja pengendalian kinerja perusahaan terniali buruk. Berdasarkan pendahuluan di atas, maka dilakukan penelitian bagaimana meningkatkan quality control menggunakan sensor DT-I/O infrared receiver 991-121, push email dan mikrokontroler arduino. 


\section{KAJIAN PUSTAKA}

\section{A. Infrared Receiver}

Infrared receiver adalah deretan cahaya gelombang elektromagnetik yang intensitas cahayanya berada di bawah cahaya tampak. Infra merah ini merupakan cahaya yang dipancarakan dari Light Emitting Diode (LED). LED infra merah dapat juga digunakan sebagai sistem keamanan dan ruang lingkup lain yang membutuhkan pancaran tak terlihat, infra merah akan mengubah energi listrik menjadi energi radiasi (pancaran panas) yang berbentuk cahaya dan tidak terlihat oleh kasat mata. Panjang gelombang infra merah antara $10^{2} \mathrm{~nm}$ sampai $10^{6} \mathrm{~nm}$ dan mempunya frekuensi antara $10^{11} \mathrm{~Hz}$ sampai $10^{14} \mathrm{~Hz}[1]$

\section{1) Sifat Cahaya Infrared:}

- Tidak tampak oleh kasat mata, tidak dapat menembus materi yang tak tembus pandang.

- Dapat ditimbulkan oleh komponen yang menghasilkan panas.

2) Spesifikasi Sensor DT-I/O Infrared Receiver 991-121:

- Tegangan kerja: +5 VDC.

- Frekuensi carrier penerima $38 \mathrm{kHz}$.

- Sensitivitas relatif puncak terjadi pada panjang gelombang $950 \mathrm{~nm}$.

- Sudut penerimaan: +/- 45 derajat.

- Memiliki 2 output (inverting dan non-inverting) yang kompatibel dengan level tegangan $T T L, C M O S$, dan $R S-232$.

- Kompatibel penuh dengan DT-51 Minimum System Ver 3.0, DT-51 PetraFuz, DT-BASIC Series, DT-51 Low Cost Series, DT-AVR Low Cost Series, dan sistem kontrol lain.

\section{3) Logika \& Pengaturan Jumper Sensor DT-I/O Infrared} Receiver 991-121:

- Sensor yang digunakan memiliki tabel logika sebagai berikut :

\begin{tabular}{|c|c|c|}
\cline { 2 - 3 } \multicolumn{1}{c|}{} & $\begin{array}{c}\text { Menerima } \mathbb{R} \\
38 \mathrm{kHz}\end{array}$ & $\begin{array}{c}\text { Tidak Menerima } \mathbb{R} \\
38 \mathrm{kHz}\end{array}$ \\
\hline $\begin{array}{c}\text { Logika } \\
\text { pada OUT }\end{array}$ & 0 & 1 \\
\hline $\begin{array}{c}\text { Logika } \\
\text { pada } \overline{\text { OUT }}\end{array}$ & 1 & 0 \\
\hline
\end{tabular}

Gambar. 1. Logika Infrared Receiver 991-121 (Innovative Electronics, 2005)[6]

- Pengaturan \& tata letak jumper adalah sebagai berikut :

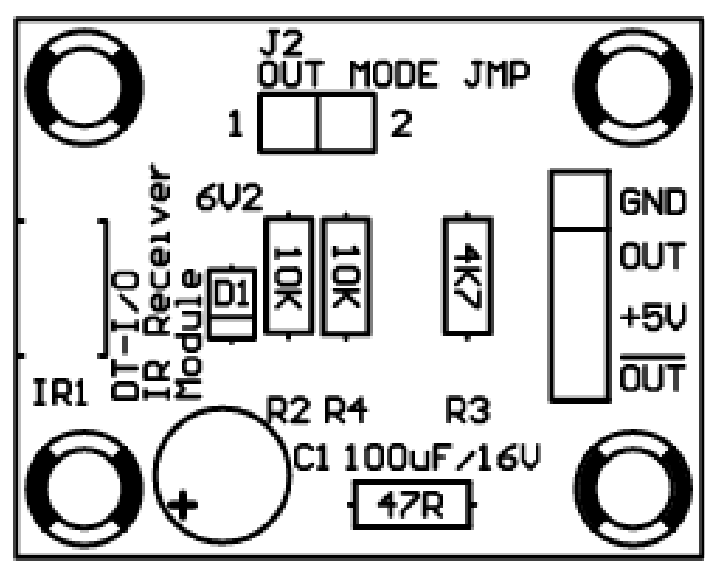

Gambar. 2. Tata Letak \& Pengaturan Jumper (Innovative Electronics, 2005)[6]
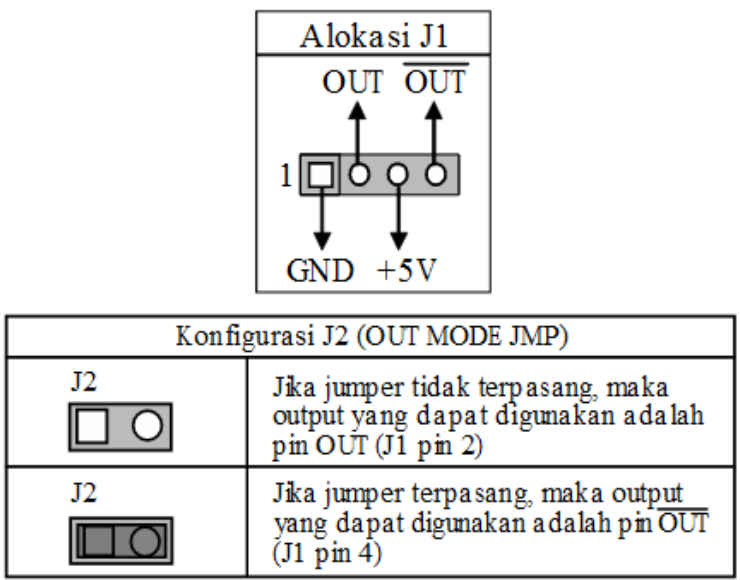

Gambar. 3. Alokasi Konfigurasi Tata Letak (Innovative Electronics, 2005)

[6]

- Rangkaian sistem digital sensor :

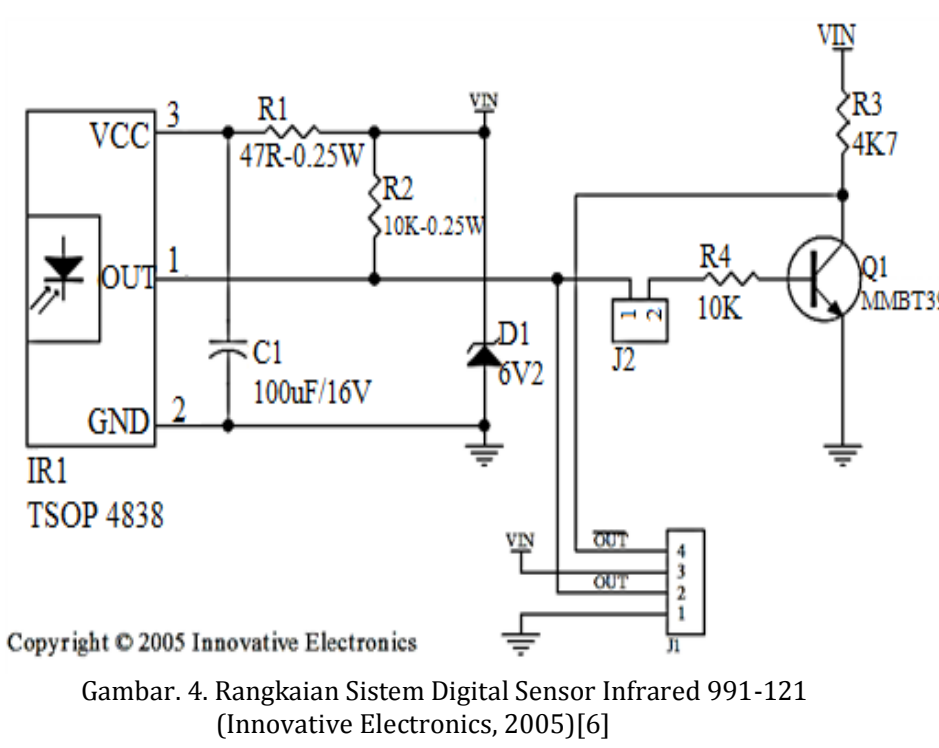

B. Arduino

Arduino adalah sebuah mikrokontroler berdasarkan ATmegal68 atau ATmega328. Memiliki 14 digital input/output pin, 6 analog input dengan $16 \mathrm{MHz}$ kristal osilator, koneksi USB, colokan listrik, ICSP dan tombol 
reset. Seluruh fitur yang diberikan mencakup semua kebutuhan yang diperlukan untuk mendukung mikrokontroler [2].

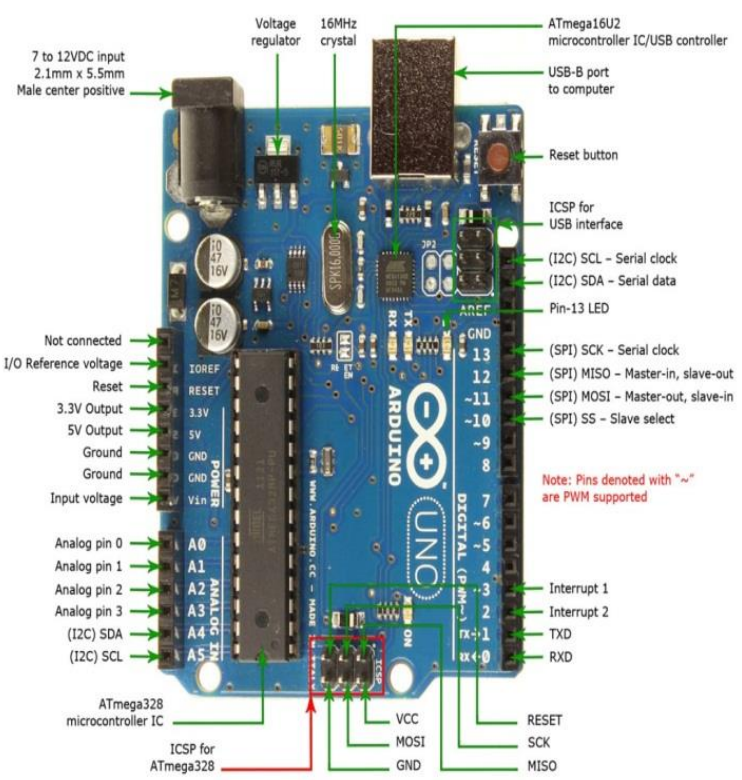

Gambar. 5. Arduino Uno (Robotmart.com, 22 Maret 2017)

\section{Quality Control}

Pengendalian dan peningkatan kualitas merupakan kegiatan yang dilakukan untuk memastikan bahwa tingkat pada produk layanan memenuhi persyaratan dan diperbaiki secara terus menerus. Sejak variabilitas sering menjadi sumber utama kualitas buruk, teknik statistik, termasuk SPC dan percobaan yang dirancang adalah alat utama untuk pengendalian dan peningkatan kualitas. Kualitas perbaikan sering dilakukan berdasarkan proyek dan melibatkan tim yang dipimpin oleh personel, dengan pengetahuan khusus tentang metode statistik dan pengalaman dalam menerapkannya. Proyek penjagaan kualitas harus dipilih sehingga mereka memiliki dampak bisnis yang signifikan dan terkait dengan tujuannya. Semua sasaran bisnis untuk kualitas diidentifikasi selama proses perencanaan [3] Pengendalian kualitas secara statistika adalah satu teknik berbeda yang didesain untuk mengevaluasi kualitas ditinjau dari sisi kesesuaian dengan spesifikasinya [7].

\section{NirCmd}

NirCmd adalah sebuah utilitas baris perintah kecil yang memungkinkan user untuk melakukan beberapa tugas yang berguna tanpa menampilkan antarmuka pengguna. Dengan menjalankan NirCmd dengan opsi baris perintah sederhana, user dapat menulis dan menghapus nilai-nilai dan kunci di registry, menulis nilai ke dalam file INI, dial ke account internet atau terhubung ke jaringan $V P N$, restart windows atau mematikan komputer, membuat shortcut ke file, mengubah dibuat/tanggal modifikasi dari file, mengubah pengaturan tampilan, mematikan monitor, buka pintu drive $C D-R O M$, dan lebih banyak lagi [4].

\section{E. E-mail}

E-mail (electronic mail) adalah surat dalam bentuk elektronik. E-mail merupakan salah satu fasilitas atau aplikasi internet yang paling banyak digunakan dalam hal surat menyurat. Hal ini dikarenakan e-mail merupakan alat komunikasi yang murah, cepat, dan efisien. Menggunakan $e$ mail dapat mengirimkan pesan dalam bentuk surat elektronik ke seluruh dunia dalam waktu yang sangat cepat dan biaya yang murah [5].

\section{ANALISIS MASALAH, SOLUSI MASALAH DAN PERANCANGAN}

\section{A. Analisis \& Solusi Masalah}

1) Analisis Masalah: Berdasarkan hasil observasi dan wawancara yang dilakukan oleh peneliti pada PT Multiprima Food, perusahaan didirikan pada tahun 2000 oleh Bapak Halim Susanto di dalam melakukan proses pengiriman barang pada PT MULTIPRIMA FOOD masih melakukan sistem manual, sehingga proses pengiriman dan pengecekan memakan waktu lama. Pada pergudangan sendiri memiliki 2 divisi yang berbeda yaitu divisi penjualan dan divisi pengiriman. Bagian pengiriman merupakan bagian yang melakukan pengecekan atas makanan yang rusak agar tidak dikirim atau diterima oleh pelanggan, karena makanan yang dibeli oleh pelanggan akan dijual kembali. Berdasarkan analisa masalah yang ada, peneliti mencoba untuk menciptakan inovasi baru di mana inovasi ini dijadikan solusi dari permasalahan yang ada yaitu dengan membuat sebuah teknologi untuk laporan quality control.

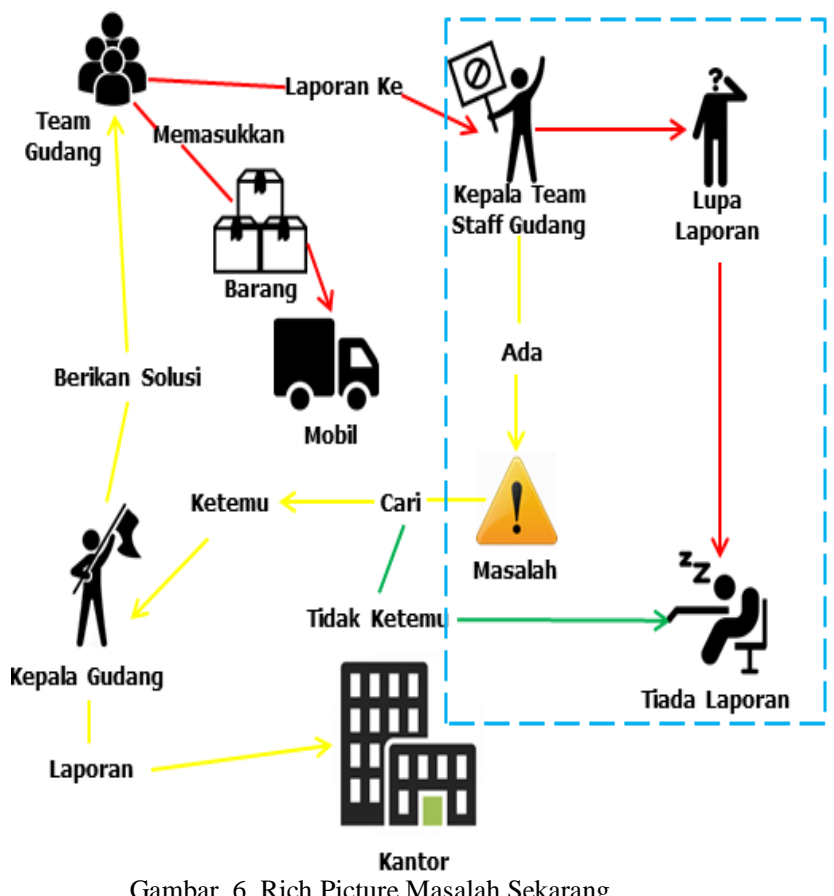

Pada Gambar 6 menjelaskan seluruh kegiatan gudang yang saat ini diterapkan pada PT MULTIPRIMA FOOD dan berikut penjelasannya: 
- Team gudang, melakukan pemasukan barang dan pelaporan pada kepala timnya saat proses memasukkan selesai ataupun terdapat masalah.

- Kepala team staff, melakukan pelaporan kepada kepala gudang jika terdapat masalah tapi jika tidak ada maka tidak melakukan pelaporan. Kendala yang ada jika saat terjadi masalah tapi kepala gudang tidak berada di tempat, eksekusi untuk penyelesaian masalah bisa tidak sesuai dengan prosedur yang diterapkan oleh perusahaan.

- Kepala gudang menerima laporan masalah yang diberikan kepala tim lalu melakukan laporan dan konfirmasi terhadap kantor terlebih dahulu. Kegiatan tersebut memakan waktu dan menurunkan kualitas pelayanan karena terlambatnya pengiriman.

2) Solusi masalah: Berdasarkan analisa masalah yang telah didapatkan dan dirangkum, peneliti melakukan penilitian dan mendapatkan solusi adalah sebagai berikut :

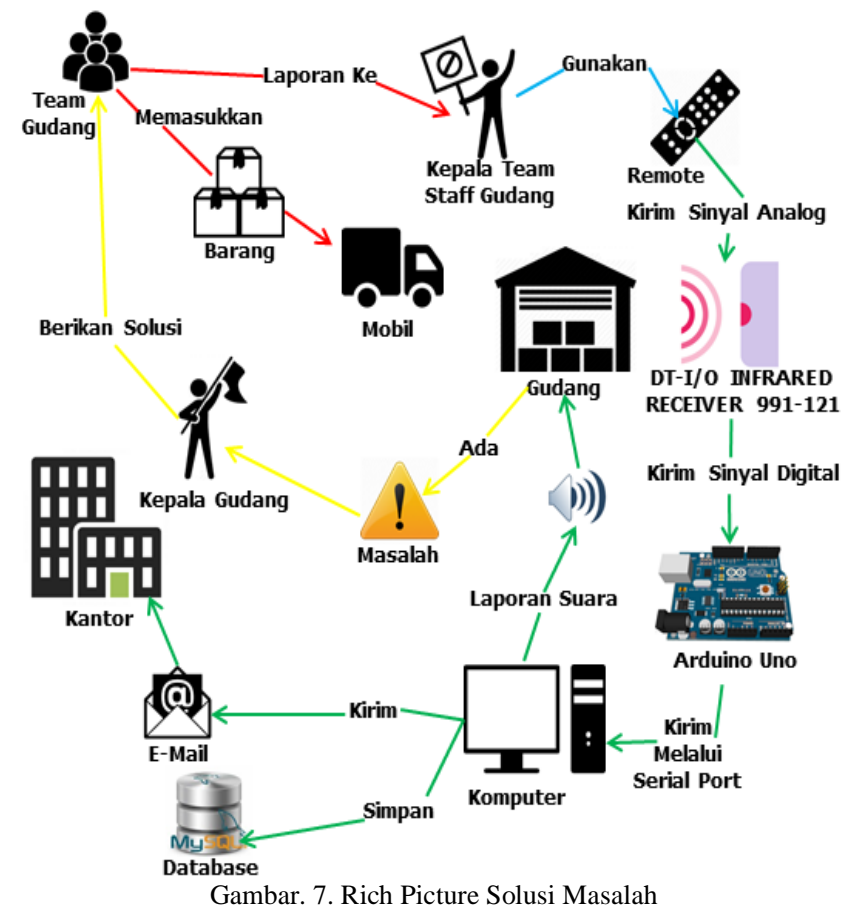

Pada Gambar 7, menjelaskan seluruh kegiatan gudang yang diaplikasikan dengan sensor DT-I/O Infrared Receiver 991-121 dan Arduino Uno dan berikut keterangannya :

- Tim gudang, melakukan pemasukan barang ke mobil sesuai dengan surat jalan/perintah yang diberikan oleh kepala staf tim gudang. Setelah selesai melakukan, terdapat masalah atau tidaknya tim gudang akan melakukan laporan terhadap kepala timnya.

- Kepala staf tim gudang, menerima seluruh laporan yang diberikan oleh timnya. Setelah menerima maka kepala tim melakukan pelaporan menggunakan remote terhadap sensor yang dipasang pada tempat yang ditentukan, tombol yang ditekan berdasarkan laporan yang diberikan bermasalah, baik-baik saja, atau masalah sudah diselesaikan.
- Remote, merupakan alat yang digunakan sebagai sarana pemberi pesan menggunakan sinar infrared kepada penerima sensor infrared.

- DT-I/O Infrared Receiver 991-121, merupakan alat yang digunakan sebagai sarana penerima pesan yang diberikan oleh remote, pesan yang diterima berdasarkan sinar infrared yang diperoleh sensor lalu dikirimkan kembali kepada Arduino Uno dengan bentuk sinyal yang sudah dikonversi dari analog ke digital.

- Arduino Uno, merupakan alat yang digunakan sebagai sarana penghubung, pemberi perintah terhadap sensor, juga sebagai pemberi pesan terhadap komputer yang terhubung dengan komputer melalui koneksi Serial Port yang ada pada komputer.

- Komputer, tempat di mana aplikasi digunakan dan terhubung dengan alat arduino, setelah komputer menerima data digital yang diberikan oleh arduino maka disesuaikan dengan ketentuan yang disediakan bahwa data tersebut akan disimpan, e-mail, dan dipublikasikan sesuai dengan sifat fungsionalnya.

- Database, tempat penyimpanan data yang digunakan oleh gudang, digunakan sebagai pelaporan harian/mingguan/bulanan sesuai dengan kebutuhan dan kebijakan perusahaan. Database ini juga tidak dapat diubah melalui aplikasi karena dibuat bersifat read-only (hanya dapat dibaca) agar user tidak dapat mengubah data.

- E-mail, push e-mail ini digunakan sebagai bukti seluruh kegiatan yang dilakukan oleh pihak gudang, pihak kantor dapat menyesuaikan dengan surat jalan yang mereka buat dan kirimkan kepada pihak gudang. Dengan ini, pihak kantor dapat langsung memberi solusi dari masalah yang ada.

- Kepala gudang, bertindak saat terjadi masalah pada kegiatan gudang yang dilakukan, dalam hal ini akan meningkatkan quality control yang ada pada perusahaan dan sekaligus pemantauan pada pihak kantor.

\section{B. Rancangan}

1) Rancangan Kerja Alat dan User: Pada Gambar 8 menjelaskan seluruh hubungan antara user, alat, dengan komputer yang diaplikasikan dengan komputer : 


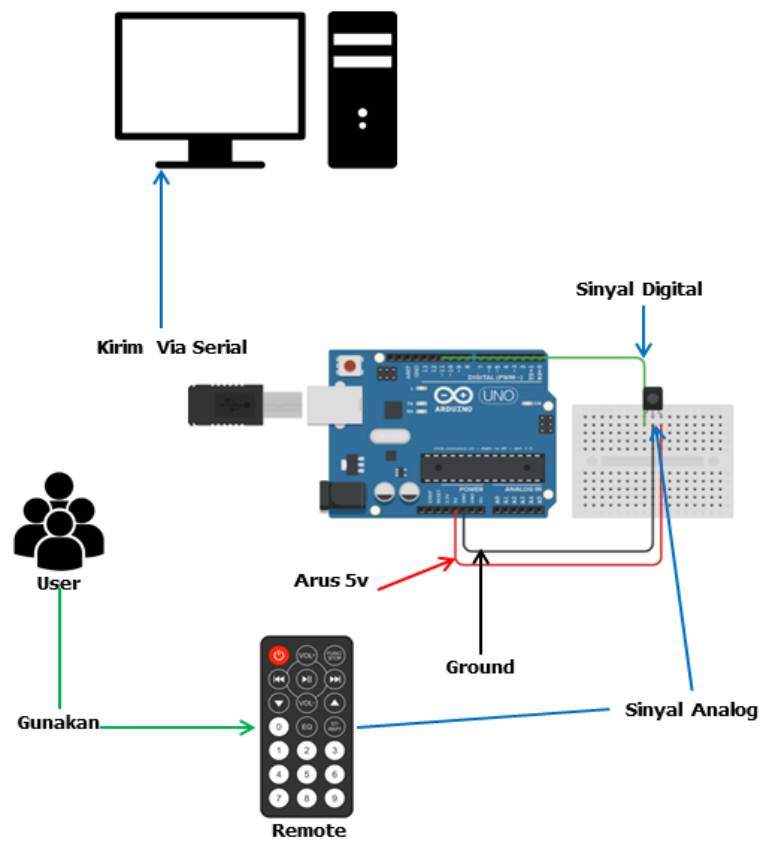

Gambar. 8. Diagram Kerja Alat Dan User

Berdasarkan Gambar 8, berikut adalah penjelasan masing-masing icon yang ada pada gambar :

- Komputer terhubung dengan arduino menggunakan serial port USB dan terinstal driver penghubung yang disediakan langsung oleh www.arduino.cc.

- Arduino terhubung dengan sensor menggunakan kabel jumper yang dipasangkan pada digital receiver (11), $5 \mathrm{v}$, dan GND yang terdapat pada board arduino.

- User menggunakan remote, lalu ditekan tombolnya dan diarahkan pada sensor IR sebagai penerima perintah.

- Setelah sensor $I R$ menerima sinyal analog dari remote dan $A D C$, sensor tersebut mengirimkan kembali kepada arduino untuk diproses melalui digital receiver (11).

- Setelah arduino menerima sinyal digital dari sensor $I R$, arduino mengirimkan sinyal kepada komputer melalui serial port USB yang telah terhubung dengan komputer.

- Komputer yang menerima sinyal digital dari arduino langsung melakukan perintah sesuai dengan program yang telah dibuat developer.

2) Rancangan Modul Sensor DT I/O Infrared Receiver 991121 Dengan Arduino: Sensor DT I/O Infrared Receiver 991121 mempunyai 4 pin, yaitu $G N D, O U T, 5 V+, O U T$. Pin-pin tersebut dihubungkan arduino uno r3 menggunakan kabel jumper. Berikut adalah koneksi sensor ke arduino :

- Pin OUT dari sensor dengan pin Digital 11 arduino.

- Pin 5V+ dari sensor dengan pin 5V arduino.

- Pin GND dari sensor dengan pin GND arduino.

3) Rancangan Remote Infrared: Karena tiap-tiap peralatan elektronik mempunyai protokol yang berbeda, maka diperlukan diperlukan banyak remote control untuk mengatur masing-masing perangkat elektronik tersebut. Karena itu, muncul perangkat yang dinamakan Universal
Remote Control. Perangkat ini yang akan digunakan peneliti kepada sensor. Berikut adalah gambar dan fungsi tombol yang diatur oleh penulis :

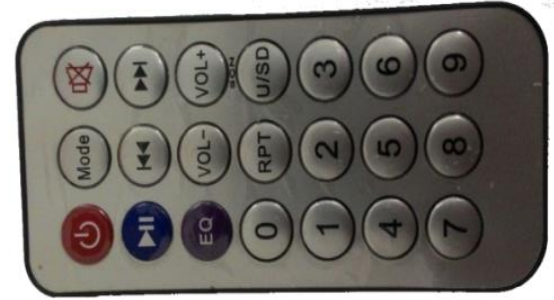

Gambar. 9. Remote Untuk Sensor DT-I/O Infrared Receiver 991-121

TABEL I

TOMBOL DAN FUNGSINYA

\begin{tabular}{|c|c|}
\hline Tombol & Fungsi Simbol \\
\hline & $\begin{array}{l}\text { Mengecilkan suara pada pc ataupun } \\
\text { laptop. }\end{array}$ \\
\hline & $\begin{array}{c}\text { Membesarkan suara pada pc ataupn } \\
\text { laptop. }\end{array}$ \\
\hline & Nyala/Matikan suara. \\
\hline & $\begin{array}{l}\text { Notifikasi sedang melakukan pemasukan } \\
\text { barang pada truk pertama. }\end{array}$ \\
\hline & $\begin{array}{l}\text { Notifikasi sedang melakukan pemasukan } \\
\text { barang pada truk kedua. }\end{array}$ \\
\hline & $\begin{array}{l}\text { Notifikasi sedang melakukan pemasukan } \\
\text { barang pada truk ketiga. }\end{array}$ \\
\hline & $\begin{array}{c}\text { Notifikasi bahwa pemasukan barang } \\
\text { pada truk pertama sudah selesai dan tidak ada } \\
\text { masalah. }\end{array}$ \\
\hline & $\begin{array}{c}\text { Notifikasi bahwa pemasukan barang } \\
\text { pada truk kedua sudah selesai dan tidak ada } \\
\text { masalah. }\end{array}$ \\
\hline & $\begin{array}{c}\text { Notifikasi bahwa pemasukan barang } \\
\text { pada truk ketiga sudah selesai dan tidak ada } \\
\text { masalah. }\end{array}$ \\
\hline & $\begin{array}{l}\text { Notifikasi bahwa pemasukan barang } \\
\text { pada truk pertama mengalami masalah. }\end{array}$ \\
\hline & $\begin{array}{l}\text { Notifikasi bahwa pemasukan barang } \\
\text { pada truk kedua mengalami masalah. }\end{array}$ \\
\hline & $\begin{array}{l}\text { Notifikasi bahwa pemasukan barang } \\
\text { pada truk ketiga mengalami masalah. }\end{array}$ \\
\hline
\end{tabular}

C. Instalasi Modul Sensor DT I/O Infrared Receiver 991-121

Instalasi sensor DT I/O Infrared Receiver 991-121 dapat dilakukan dengan mudah, sensor $I R$ receiver yang peneliti gunakan yaitu komunikasi Analog Digital Convertion (ADC) untuk mengirim data dari sensor ke arduino uno r3. Gambar 10 merupakan tampilan dari instalasi sensor DT I/O Infrared Receiver 991-121. 


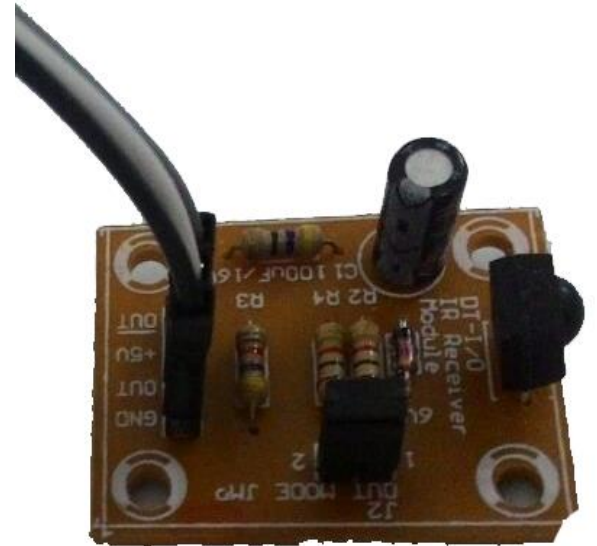

Gambar. 10. Instalasi Modul Sensor DT-I/O Infrared Receiver 991-121

Sensor DT I/O Infrared Receiver 991-121 mempunyai 4 pin, yaitu GND, OUT, 5V+, OUT. Pin-pin tersebut dihubungkan arduino uno $r 3$ menggunakan kabel jumper. Berikut adalah koneksi sensor ke arduino:

- Pin OUT dari sensor dengan pin Digital 11 arduino.

- Pin 5V+ dari sensor dengan pin 5V arduino.

- Pin GND dari sensor dengan pin GND arduino.

Untuk melihat koneksi modul sensor DT I/O Infrared Receiver 991-121 dengan arduino lebih jelasnya bisa dilihat pada Gambar 11.

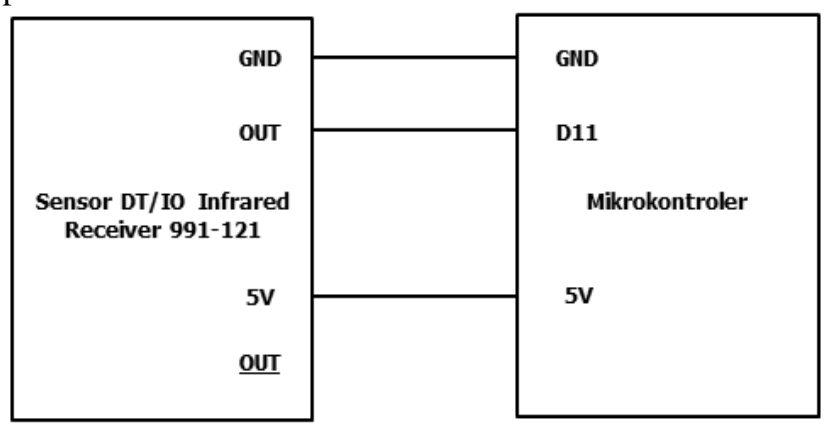

Gambar. 11. Koneksi Modul Sensor DT-I/O Infrared Receiver 991-121

\section{D.Instalasi Rangkaian Keseluruhan}

Setelah seluruh rangkaian dan modul dirakit dan saling terhubung. Selanjutnya peneliti melakukan tinjauan agar tidak terjadi kesalahan koneksi dan pemasangan kabel. Pada Gambar 12 merupakan gambar dari alat sensor DT-I/O Infrared Receiver 991-121 dengan mikrokontroler yang telah dibuat.

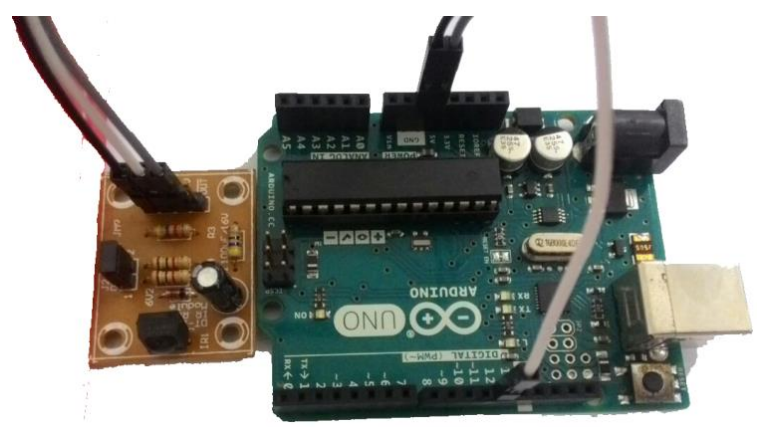

Gambar. 12. Tampilan Keseluruhan Alat

\section{E. Pengujian Alat Sensor DT-IO Infrared Receiver 991-121}

Pengujian ini dilakukan menggunakan Software IDE Arduino, sebelumnya alat telah dihubungkan dengan laptop melalui kabel USB. Berikut adalah hasil pengujian alat yang telah dilakukan. Proses Receiving, Gambar 13 menampilkan output dari mikrokontroler jika sensor sedang menerima infrared.

\begin{tabular}{|c|c|c|}
\hline (2) $\operatorname{COM} 3$ (Arduino/Genuino Uno) & & \begin{tabular}{l|l|l}
$口$ & a & $x$ \\
\end{tabular} \\
\hline 1 & & Send \\
\hline 16748655 & & . \\
\hline 16738455 & & \\
\hline 16750695 & & \\
\hline 16756815 & & \\
\hline 16724175 & & \\
\hline 16718055 & & - \\
\hline 16743045 & &  \\
\hline 16716015 & & \\
\hline 16726215 & & \\
\hline 16734885 & & $\equiv$ \\
\hline 16728765 & & \\
\hline 16730805 & & \\
\hline 16732845 & & \\
\hline ( Autoscroll & No line ending - & - 9600 baud \\
\hline
\end{tabular}

Gambar. 13. Testing Sensor Dari Remote Gambar 9

\section{IMPLEMENTASI, HASIL DAN PEMBAHASAN}

\section{A. Prosedur Operasional}

Setelah sistem selesai dirancang dengan benar dan diobservasi sehingga tidak ada yang salah dalam pemasangan dan koneksi dari setiap sensor yang dipergunakan, langkah selanjutnya adalah menghubungkan sensor kepada arduino, dengan komputer menggunakan kabel USB agar dapat bertukar informasi yang diperlukan. Aplikasi sensor DT-I/O Infrared Receiver 991-121 akan menerima data dari arduino dan mengirim data ke arduino melalui kabel USB tersebut.

Setelah semua terhubung dengan baik selanjutnya aplikasi sensor DT-I/O Infrared Receiver 991-121 dapat dijalankan pada dashboard aplikasi tersebut memiliki port untuk koneksi dengan arduino, langkah selanjutnya klik tombol connect untuk memulai komunikasi antara aplikasi sensor DT IO Infrared Receiver 991-121 dengan arduino. Berikut adalah langkah-langkah yang harus dilakukan sebagai prosedur operasional dari aplikasi sensor $D T I O$ Infrared Receiver 991-121 yang penulis rancang:

- Memasang rangkaian sensor dan arduino dengan benar.

- Menghubungkan alat dengan komputer atau laptop dengan perantara kabel USB. Menjalankan program arduino IDE, kemudian mengunggah program yang telah dibuat ke dalam mikrokontroler.

- Menjalankan program aplikasi sensor DT IO Infrared Receiver 991-121 yang penulis rancang menggunakan Netbeans IDE 7.4.

- Melakukan login dengan menggunakan username dan password yang benar. 
- Pilih kegiatan gudang, kemudian input kembali username dan password yang benar lalu pilih login. Setelah itu pilih port serial yang benar pada aplikasi dan memilih tombol connect.

- Gunakan remote sesuai dengan kebutuhan

\section{B. Implementasi}

Pengujian sistem ini bertujuan untuk mengetahui tingkat efisiensi, efektivitas, dan keakuratan penerimaan infrared pada pengujian sensor $I R$. Uji coba simulasi bertujuan untuk mengetahui sistem dapat bekerja dengan baik atau tidak, sehingga dapat dipertimbangkan tingkat elok dan reparasi yang akan dikerjakan. Hal-hal tersebut akan diketahui jika sudah dilakukan simulasi uji coba sistem.

1) Tampilan Dari Sisi User Atau Pengguna: Tampilan Layar form login aplikasi, untuk dapat menggunakan aplikasi maka harus login terlebih dahulu dengan menggunakan username dan password yang telah didaftarkan. Berikut tampilantampilannya:

\section{- Tampilan Form Login}

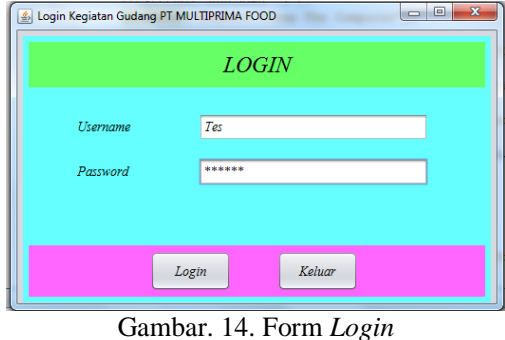

- Notifikasi Password Benar



Gambar. 15. Notifikasi Jika Username dan Password Benar

- Notifikasi Password Salah, jika pengguna mengalami kesalah secara terus-menerus maka diperlukan bantuan dari Administrator untuk mengetahui password.

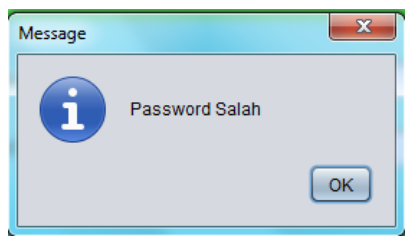

Gambar. 16. Notifikasi Jika Username dan Password Salah

- Tampilan Form Kegiatan Gudang

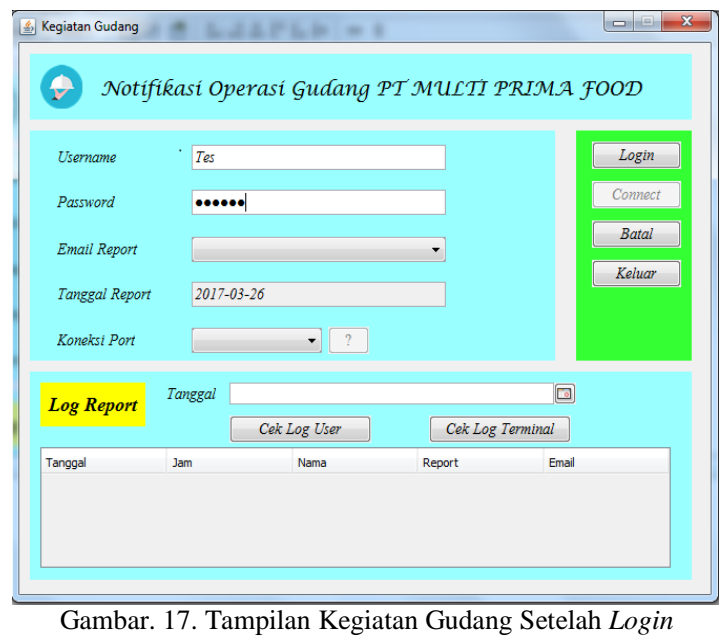

2) Tampilan dari Sisi Admin: Tampilan yang berbeda dengan fitur yang dimiliki oleh pegawai biasa. Untuk tampilan login, kegiatan gudang memiliki tampilan yang sama. Berikut tampilan-tampilannya:

- Tampilan menu utama, setelah admin melakukan login dengan benar, maka akan tampil menu utama yang hanya dimiliki oleh user dengan role admin.

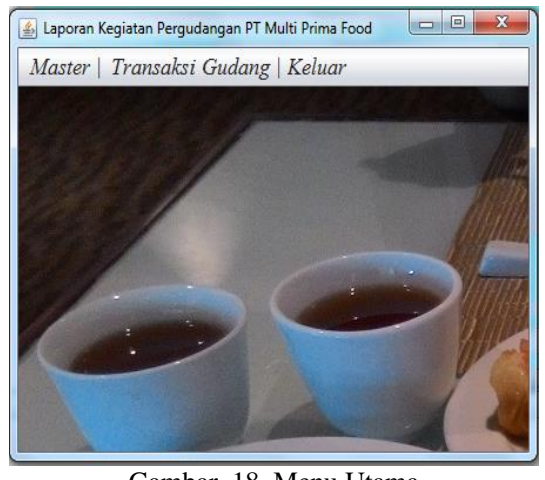

- Tampilan Master Staff, dari menu utama, admin bisa melakukan pengisian data staff gudang sebagai pendataan atau pemberian akses user

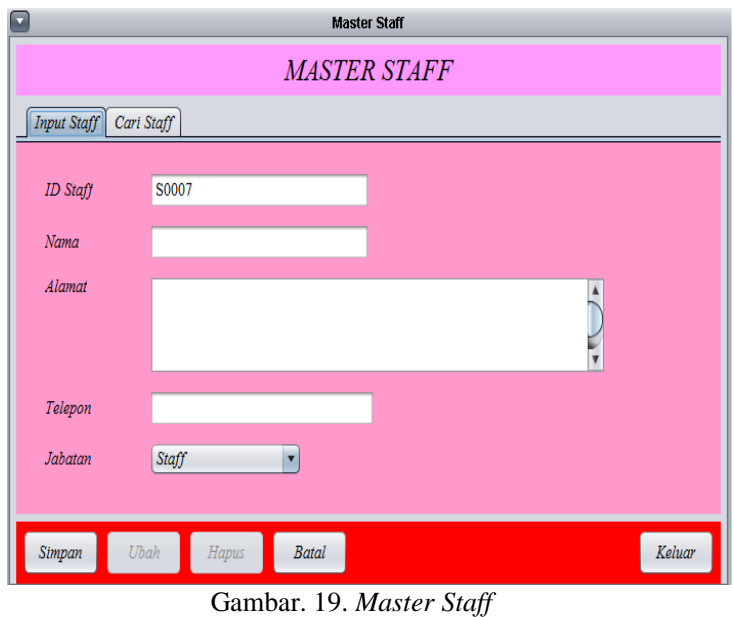


Setelah data staff dimasukkan, admin dapat mencari data tersebut untuk dimodifikasi atau dihapus seperti Gambar 20. Admin dapat melakukan pencarian dan penelaahan data berdasarkan ID, Nama, Alamat, Telepon ataupun Jabatan. Pencarian bisa dilakukan lebih dari satu kategori.

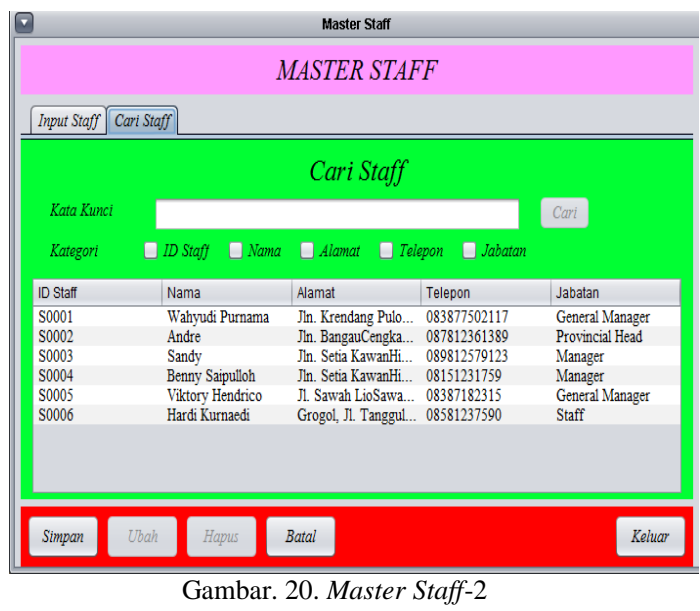

Jika user saat menyimpan, masih belum mengisi data, baik nama, alamat ataupun telepon maka akan tampil notifikasi. Notifikasi seperti di bawah ini
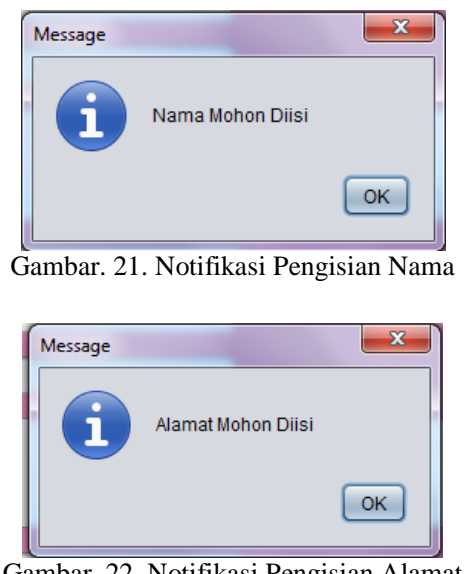

Gambar. 22. Notifikasi Pengisian Alamat
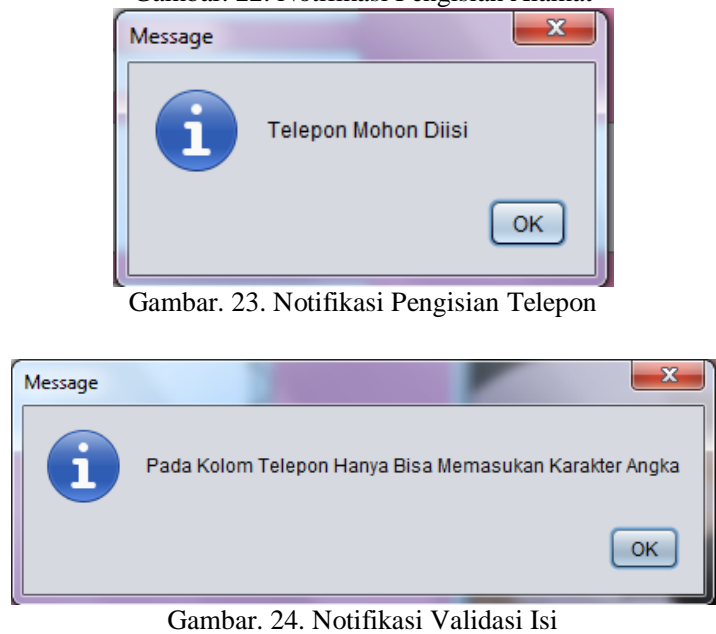

Gambar. 24. Notifikasi Validasi Isi
- Tampilan master user, tampilan master user, dari menu utama, admin dapat melakukan pembuatan atau modifikasi data user dan untuk pembuatan diharuskan terlebih dahulu mengisi data staff dikarenakan user yang diinput memiliki spesifikasi data staff. Setiap layar memiliki notifikasi pengisian yang sama dengan master staff.

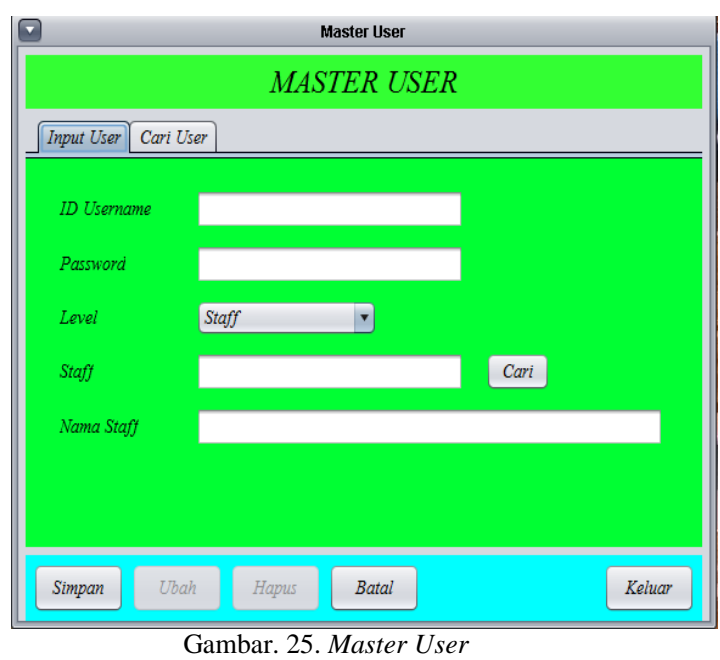

Saat memasukkan data, admin diharuskan memilih data staf yang akan dimasukkan dengan tombol cari maka akan tampil data staf seperti Gambar 26.

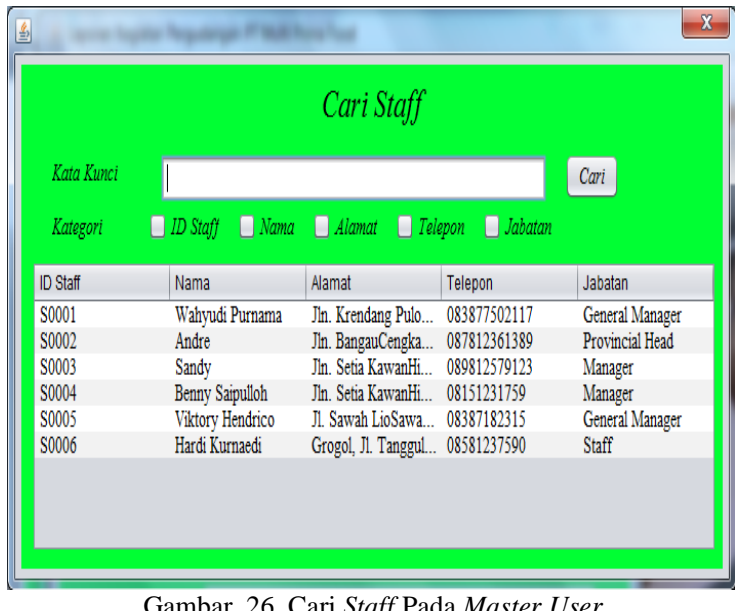

Setelah data user dimasukkan, admin dapat mencari data tersebut untuk dimodifikasi atau dihapus seperti Gambar 27. Admin dapat melakukan pencarian data. 


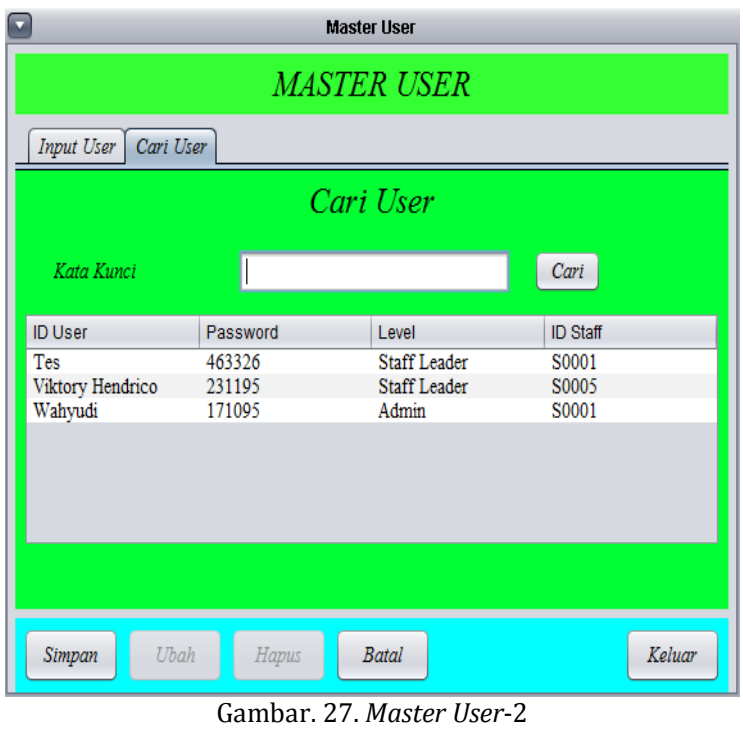

Jika user saat menyimpan, masih belum mengisi data, baik user, password ataupun staff ID maka akan tampil notifikasi.

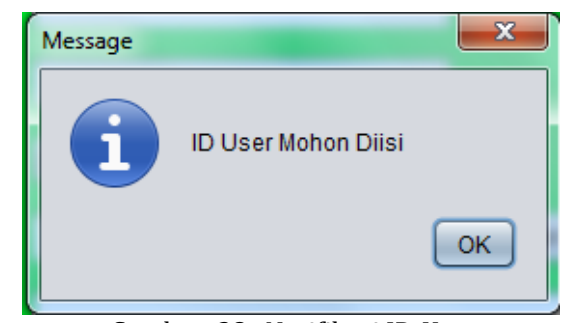

Gambar. 28 . Notifikasi ID User

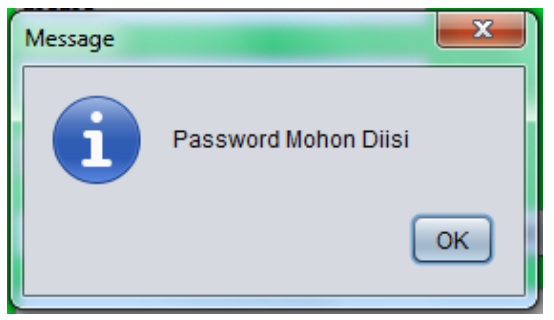

Gambar. 29. Master Isi Password

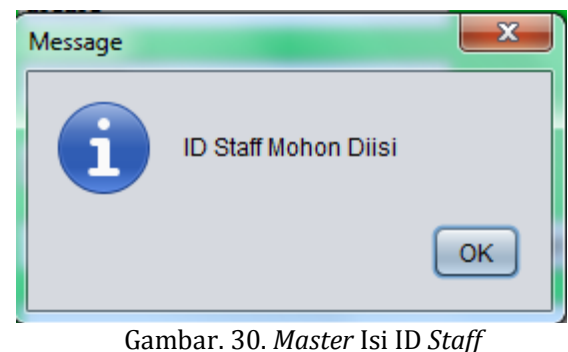

- Tampilan Master Email, dari menu utama, admin dapat melakukan pembuatan atau modifikasi data email agar dapat melakukan transaksi kegiatan gudang. E-mail ini akan digunakan sebagai tujuan penerima pelaporan dari kegiatan gudang.

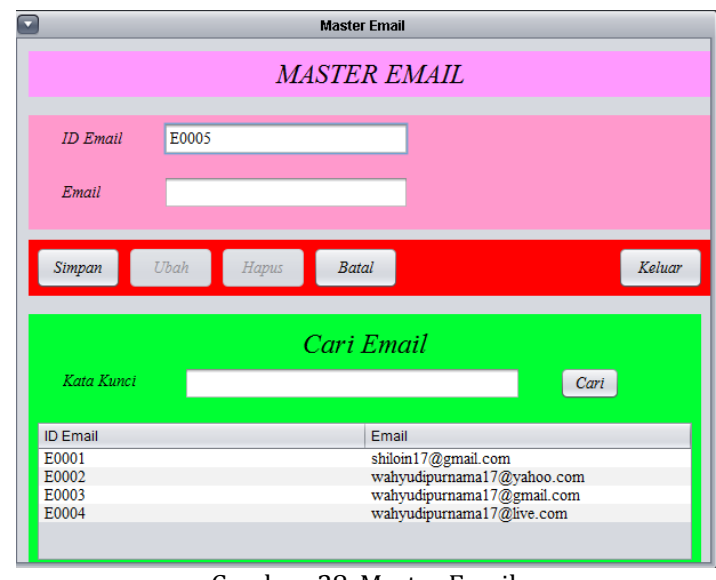

Gambar. 28. Master Email.

\section{Hasil}

Dari rancangan yang telah dibuat, peneliti melakukan uji coba dengan menggunakan nomor 2, 4 dan 8 pada Universal Remote Control. Berikut adalah gambar hasil uji coba yang telah dilakukan :

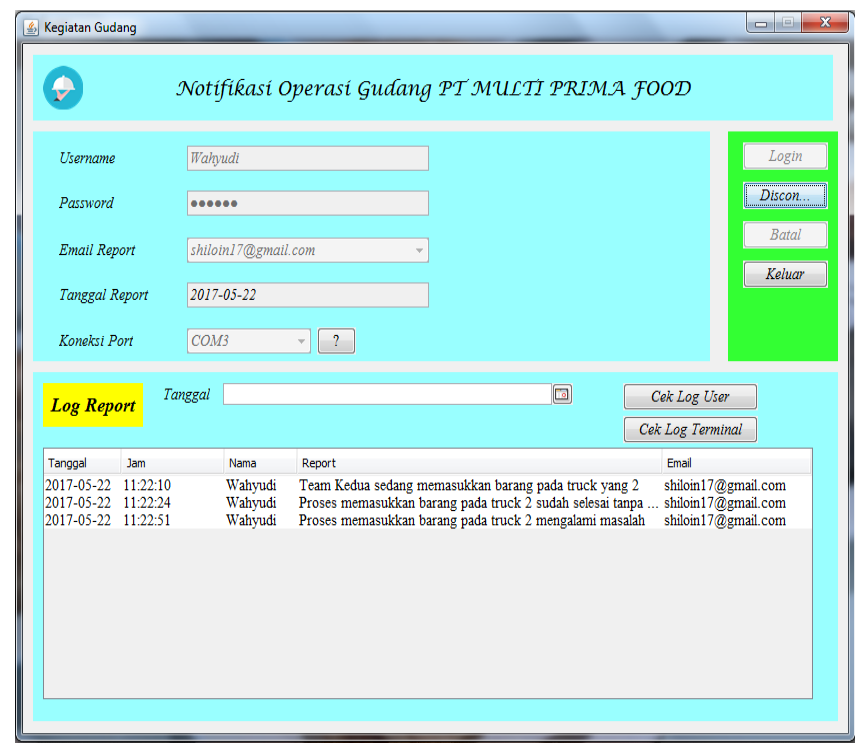

Gambar. 29. Form Pengaplikasian Solusi Masalah

Setelah pelaporan tersimpan dan pengujian suara berhasil dilakukan (tombol nomor 2 menghasilkan suara "right now the second team was putting the goods on the second truck"), maka program mengirimkan e-mail. Setelah program melakukan email, berikut adalah salah contoh satu hasil bukti e-mail atas uji coba yang dilakukan :

\section{Pada truk nomor 2 mengalami masalah $\square \quad \operatorname{lnbox} x \quad$ 要}

shiloin17@gmail.com

6:16 PM (2 hours ago)

to me $v$

Proses memasukkan barang terdapat masalah untuk truck : 2 tanggal2017-03-26

Gambar. 30. Form Hasil Email 


\section{D.Tabel Pengujian}

Tabel merupakan hasil uji coba sistem yang telah dirancang. Sistem ini tentu mempunyai hasil baik dan tidak secara tersendiri jika ditinjau dari kebutuhan penggunaan yang beragam dengan kondisi dan situasi berbeda-beda

TABEL III

HASIL PENGUJIAN APLIKASI DAN SENSOR

\begin{tabular}{|c|c|c|c|c|}
\hline \multirow{2}{*}{ No } & \multirow{2}{*}{ Tombol } & \multirow{2}{*}{ Ekspetasi } & \multicolumn{2}{|r|}{ Hasil } \\
\hline & & & Bisa & Keterangan \\
\hline \multirow{3}{*}{1} & \multirow[t]{3}{*}{ Arduino } & $\begin{array}{l}\text { Terhubung } \\
\text { dengan } \\
\text { sensor }\end{array}$ & $\checkmark$ & Berhasil \\
\hline & & $\begin{array}{l}\text { Terhubung } \\
\text { dengan } \\
\text { komputer }\end{array}$ & $\checkmark$ & Berhasil \\
\hline & & $\begin{array}{l}\text { Dapat dicari } \\
\text { dengan serial } \\
\text { port }\end{array}$ & $\checkmark$ & Berhasil \\
\hline \multirow[t]{6}{*}{2} & \multirow[t]{6}{*}{ Sensor } & $\begin{array}{l}\text { Dapat } \\
\text { digunakan } \\
\text { dalam jarak } \\
1 \text { meter }\end{array}$ & $\checkmark$ & Berhasil \\
\hline & & $\begin{array}{l}\text { Dapat } \\
\text { digunakan } \\
\text { dalam jarak } \\
2 \text { meter }\end{array}$ & $\checkmark$ & Berhasil \\
\hline & & $\begin{array}{l}\text { Dapat } \\
\text { digunakan } \\
\text { dalam jarak } \\
3 \text { meter }\end{array}$ & $\checkmark$ & Berhasil \\
\hline & & $\begin{array}{l}\text { Dapat } \\
\text { digunakan } \\
\text { dalam jarak } \\
4 \text { meter }\end{array}$ & $\checkmark$ & Berhasil \\
\hline & & $\begin{array}{l}\text { Dapat } \\
\text { digunakan } \\
\text { dalam jarak } \\
5 \text { meter }\end{array}$ & & Tidak Bisa \\
\hline & & $\begin{array}{l}\text { Dapat } \\
\text { digunakan } \\
\text { jika kurang } \\
\text { lebih dari } 5 \\
\text { meter dan } \\
\text { terhalang } \\
\text { objek }\end{array}$ & & $\begin{array}{ll}\text { - } & \text { Jika } \\
\text { objek } \\
\text { penghala } \\
\text { ng } \\
\text { plastik } \\
\text { dengan } \\
\text { ketebala } \\
\text { n<1 cm } \\
\text { masih } \\
\text { bisa } \\
\text { Penghala } \\
\text { ng selain } \\
\text { plastik } \\
\text { memiliki } \\
\text { kemungk } \\
\text { inan } \\
\text { berhasil/ } \\
\text { tidak }\end{array}$ \\
\hline 3 & Tombol 1 & $\begin{array}{l}\text { Simpan, } \\
\text { Email, Suara }\end{array}$ & $\checkmark$ & Berhasil \\
\hline 4 & Tombol 2 & $\begin{array}{l}\text { Simpan, } \\
\text { Email, Suara }\end{array}$ & $\checkmark$ & Berhasil \\
\hline 5 & Tombol 3 & $\begin{array}{l}\text { Simpan, } \\
\text { Email, Suara }\end{array}$ & $\checkmark$ & Berhasil \\
\hline 6 & Tombol 4 & $\begin{array}{l}\text { Simpan, } \\
\text { Email, Suara }\end{array}$ & $\checkmark$ & Berhasil \\
\hline
\end{tabular}

\begin{tabular}{|c|c|c|c|c|}
\hline 7 & Tombol 5 & $\begin{array}{l}\text { Simpan, } \\
\text { Email, Suara }\end{array}$ & $\checkmark$ & Berhasil \\
\hline 8 & Tombol 6 & $\begin{array}{l}\text { Simpan, } \\
\text { Email, Suara }\end{array}$ & $\square$ & Berhasil \\
\hline 9 & Tombol 7 & $\begin{array}{l}\text { Simpan, } \\
\text { Email, Suara }\end{array}$ & $\checkmark$ & Berhasil \\
\hline 10 & Tombol 8 & $\begin{array}{l}\text { Simpan, } \\
\text { Email, Suara }\end{array}$ & $\checkmark$ & Berhasil \\
\hline 11 & Tombol 9 & $\begin{array}{l}\text { Simpan, } \\
\text { Email, Suara }\end{array}$ & $\square$ & Berhasil \\
\hline 12 & Suara+ & $\begin{array}{l}\text { Meningkatka } \\
\text { n suara }\end{array}$ & $\checkmark$ & Berhasil \\
\hline 13 & Suara- & $\begin{array}{l}\text { Mengecilkan } \\
\text { suara }\end{array}$ & $\checkmark$ & Berhasil \\
\hline 14 & Mute/On & $\begin{array}{l}\text { Mematikan/h } \\
\text { idup suara }\end{array}$ & $\checkmark$ & Berhasil \\
\hline \multirow[t]{3}{*}{15} & \multirow[t]{3}{*}{ Database } & $\begin{array}{l}\text { Terkoneksi } \\
\text { dengan } \\
\text { program }\end{array}$ & $\checkmark$ & Berhasil \\
\hline & & $\begin{array}{l}\text { Dapat } \\
\text { menyimpan }\end{array}$ & $\square$ & Berhasil \\
\hline & & $\begin{array}{l}\text { Dapat } \\
\text { menampilka } \\
\mathrm{n} \text { data }\end{array}$ & $\checkmark$ & Berhasil \\
\hline 16 & Email & $\begin{array}{l}\text { Dapat } \\
\text { mengemail }\end{array}$ & $\square$ & Berhasil \\
\hline 17 & Suara & $\begin{array}{l}\text { Laporan } \\
\text { pengumuma } \\
\text { n suara }\end{array}$ & $\square$ & Berhasil \\
\hline
\end{tabular}

\section{KESIMPULAN}

Berdasarkan evaluasi hasil pengujian perangkat sensor DT/IO Infrared Receiver 991-121 ini maka penulis membuat kesimpulan :

- Quality Control gudang pada PT MULTIPRIMA FOOD dapat ditingkatkan dengan aplikasi yang dibuat peneliti, karena seluruh kegiatan akan dilaporkan baik bermasalah ataupun tidak.

- Timbulnya masalah saat memasukkan barang ke gudang dapat langsung ditindak, dan ke lokasi langsung oleh kepala gudang. Hasil kendala dapat diberitahukan langsung melalui remot, untuk lebih spesifikasi masalah dan tindakan dilakukan secara terpisah dari aplikasi yang dibuat.

- Pemberitahuan untuk kantor tidak akan memakan waktu, juga terlewatkan dikarenakan pengunaan remot dan sensor langsung menyimpan database dan juga meng-email bahkan pengumuman suara yang didengar langsung oleh 1 gudang.

- Notifikasi suara yang dikeluarkan pada setiap penggunaan remote berjalan dengan baik, kepala gudang dapat memantau seluruh kegiatan pada gudang lebih maksimal dan cepat.

\section{DAFTAR PUSTAKA}

[1] Wira. G, Prama, Hari Utami, Ferry \& Cheng, Ei. 2013. Penerapan Infrared Remote Control Dalam Mengoperasikan Aplikasi Pada Sistem Operasi Windows XP. Bengkulu : Jurnal Media Infotama.

[2] Marathe, Rhuta, Kulkarni, Amura \& Devkar, Utkarsha. 2014. Portable Automatic Height Detector. International Journal of Science, Engineering and Technology Research (IJSETR).

[3] Montgomery, Douglas C. 2001. Introduction to Statistical Quality Control. 4th Edition. New York: John Wiley \& Sons, Inc. 
[4] Sofer, Nir (2003). NirCmd v.2.81. Tersedia : http://www.nirsoft.net/utils/nircmd.html. 22 Maret 2017.

[5] F. Leao, Cibeli, T. Formoso, Carlos \& L. Isatto, Eduardo. 2014. Integrating Production And Quality Control With Support Of Information Technology. Brazil : Building Innovation Research Unit (NORIE).

[6] (2005) Innovative Electronics website. [Online]. Tersedia http://www.innovativeelectronics.com/innovative_electronics/downloa d_files/manual/Manual\%20DT-IO\%20IR\%20Receiver.pdf

[7] Richard B. Chase, Nicholas J. Aquilano and F. Robert Jacobs. 2001. Operations Management For Competitive Advantage. 9th Edition. New York: McGraw-Hill Companies. 